Цитирование: Буйденок Ю.В. Рекомендации по профилактике и лечению последствий экстравазации противоопухолевых препаратов. Злокачественные опухоли: Практические рекомендации RUSSCO \#3s2, 2021 (том 11). 48

\title{
РЕКОМЕНДАЦИИ ПО ПРОФИЛАКТИКЕ И ЛЕЧЕНИЮ ПОСЛЕДСТВИЙ ЭКСТРАВАЗАЦИИ ПРОТИВООПУХОЛЕВЫХ ПРЕПАРАТОВ
}

Автор: Буйденок Ю.В.

Ключевые слова: противоопухолевая химиотерапия, венозный доступ, экстравазация, сосудистые катетеры

Экстравазация - процесс случайного попадания лекарственных препаратов внутрикожно и/или в подкожную клетчатку в месте сосудистого доступа (внутривенного или внутриартериального). Экстравазация сопровождается различными осложнениями, которые зависят от типа препарата, его количества, скорости и длительности введения с выходом во внесосудистое пространство. Экстравазация считается сравнительно редким ятрогенным осложнением инфузионной терапии, которое носит эпизодический характер. В связи с этим нет достоверного количества данных об истинной частоте, тяжести и последствиях экстравазации. Специфического лечения экстравазации нет, поэтому следует с максимальным вниманием относиться к профилактике этого редкого, но в отдельных случаях, тяжелого осложнения инфузионной терапии и правильно выбирать устройство венозного доступа для онкологического пациента. В зависимости от характера осложнений экстравазации и степени тяжести могут потребоваться наблюдение, консервативное лечение, а также хирургические вмешательства вплоть до кожно-пластических операций. Важно помнить, что при выполнении инфузионной терапии противоопухолевыми препаратами, степень повреждения при экстравазации зависит от вида лекарственного средства, его химическофизических свойств ( $\mathrm{pH}$, осмолярности), механизма его действия, концентрации и объема. Применение инфузионной системы центрального венозного доступа многократно снижает вероятность экстравазации, но не является гарантией предупреждения этого осложнения. В связи с этим необходимо знать алгоритмы выбора того или иного устройства венозного доступа, способы профилактики, своевременной диагностики и первой помощи при экстравазации. В статье использованы рекомендации Infusion Therapy Standards of Practice (INS, 2021 г.), SACT NSH Network Guidelines (2017 г.), ESMO-EONS (2020 г.), и данные отдельных сообщений, дополненные и адаптированные к условиям российского здравоохранения. 


\section{1. КЛАССИФИКАЦИЯ ПРОТИВООПУХОЛЕВЫХ ПРЕПАРАТОВ ПО ТИПУ ПОВРЕЖДАЮЩЕГО ДЕЙСТВИЯ}

В большинство схем и режимов противоопухолевой терапии входят цитостатические противоопухолевые препараты (цитостатики). Механизм действия цитостатиков неизбирателен, поэтому они оказывают прямое повреждающее действие не только на опухолевые, но и на нормальные клетки организма, в первую очередь, клетки, для которых характерна высокая способность к пролиферации. При внутривенных инфузиях цитостатики поступают в высоких концентрациях и оказывают прямое токсическое действие на интиму и эндотелиальный слой вен, кроме того, цитотоксические препараты изменяют состав и реологические свойства крови (повышенная кровоточивость, повышенное тромбообразование). Это увеличивает риск венозных осложнений (болевой синдром и жжение по ходу вены во время инфузии, флебиты, тромбофлебиты, флебосклероз, облитерация вен, экстравазация и некроз окружающих тканей). Флебит и экстравазация - частые и нередко связанные осложнения противоопухолевой инфузионной терапии.

По типу повреждающего действия все противоопухолевые препараты делятся на:

1) Везиканты - лекарственные средства с кожно-нарывным действием, могут разрушить стенку сосудов и вызывать раздражение и некроз окружающих тканей.

Везиканты подразделяются на:

- ДНК связывающие

- ДНК не связывающие

2) Ирританты (раздражающие) - лекарственные средства, раздражающие внутреннюю стенку сосудов, могут вызывать химические флебиты

3) Невезиканты (не кожно-нарывные) - лекарственные средства, как правило, не вызывающие раздражения или повреждения тканей, но могут вызывать боль вокруг места инъекции и по ходу вен.

4) Эксфолианты (кислоты)

5) Воспалительные

Классификация некоторых противоопухолевых препаратов в зависимости от типа повреждающего действия представлена в табл. 1.

Таблица 1. Классификация противоопухолевых препаратов в зависимости от типа повреждающего действия

\begin{tabular}{|c|c|c|c|}
\hline \multicolumn{2}{|l|}{ Везиканты } & \multirow[b]{2}{*}{ Ирританты } & \multirow[b]{2}{*}{ Невезиканты } \\
\hline ДНК-связывающие & ДНК-несвязывающие & & \\
\hline Доксорубицин & Паклитаксел & $\begin{array}{l}\text { Флуороцил (фтор- } \\
\text { урацил, 5-фторурацил) }\end{array}$ & Циклофосфамид \\
\hline Кармустин & Доцетаксел & Метотрексат & Паклитаксел+Альбумин \\
\hline Дакарбазин & Кабазитаксел & Паклитаксел+Альбумин & Метотрексат \\
\hline Даунорубицин & Трабекстидин & Цисплатин & Мышьяка триоксид \\
\hline
\end{tabular}




\begin{tabular}{|c|c|c|c|}
\hline \multicolumn{2}{|l|}{ Везиканты } & \multirow[b]{2}{*}{ Ирританты } & \multirow[b]{2}{*}{ Невезиканты } \\
\hline ДНК-связывающие & ДНК-несвязывающие & & \\
\hline Эпирубицин & Винбластин & Карбоплатин & Аспарагиназа \\
\hline Идарубицин & Винкристин & Кармустин & Блеомицин \\
\hline Митомицин & Винфлунин & Бендамустин & Бортезомиб \\
\hline Треосульфан & Винорелбин & Этопозид & Кладрибин \\
\hline Дактиномицин & & Ифосфамид & Цитарабин \\
\hline Митоксантрон & & Иринотекан & Эрибулин \\
\hline \multirow[t]{14}{*}{ Бендамустин } & & $\begin{array}{l}\text { Доксорубицин } \\
\text { липосомальный }\end{array}$ & Флударабин \\
\hline & & $\begin{array}{l}\text { Даунорубицин } \\
\text { липосомальный }\end{array}$ & Гемцитабин \\
\hline & & Мелфалан & $\begin{array}{l}\text { Моноклональные } \\
\text { антитела }\end{array}$ \\
\hline & & Митоксантрон & Пеметрексед \\
\hline & & Оксалиплатин & Ралтитрексед \\
\hline & & Темсиролимус & Тиотепа \\
\hline & & Топотекан & Интерлейкин-2 \\
\hline & & Дакарбазин & Темсилолимус \\
\hline & & Трастузумаб эмтазин & \\
\hline & & Афлиберцепт & \\
\hline & & Иксабепилон & \\
\hline & & Интерфероны & \\
\hline & & Гемцитабин & \\
\hline & & Бортезомиб & \\
\hline
\end{tabular}

\section{2. РЕКОМЕНДАЦИИ ПО МИНИМИЗАЦИИ РИСКА ЭКСТРАВАЗАЦИИ}

\section{1. Факторы риска повреждения вен}

При назначении внутривенных цитостатических противоопухолевых препаратов следует обращать внимание на факторы риска возможного повреждения вен, которые могут привести к экстравазации. К таким факторам риска относятся:

- затрудненный периферический венозный доступ у пациента (вены малого диаметра, ломкие, поврежденные вены);

- пациенты пожилого возраста и дети; 
- множественные в/в инъекции и/или взятия проб крови в анамнезе (флебосклероз, облитерация вен);

- лимфедема после удаления лимфатических узлов вследствие мастэктомии;

- периферическая нейропатия верхних конечностей;

- перенесенные экстравазации в анамнезе;

- синдром верхней полой вены;

- пациенты с нарушением уровня бодрствования, в седации, психомоторном возбуждении, с речевыми расстройствами;

- сопутствующие заболевания, приводящие к нарушению периферического кровообращения (например, сахарный диабет, гипо-и гиперкоагуляция, заболевания периферических сосудов, синдром Рейно, перенесенные ОНМК и др.);

- ожирение;

- сопутствующая лекарственная терапия (антитромбоцитарные и антикоагулянтные средства, гормоны, диуретики, антибактериальные препараты, иммуносупрессивные средства и др.).

\section{2. Алгоритм выбора сосудистого доступа у онкологического пациента}

При выборе и назначении того или иного устройства венозного доступа, при установке и эксплуатации устройств следует руководствоваться локальными правилами и процедурами, практическими руководствами и инструкциями по применению производителей таких устройств (INS 2021, Section Five: Vascular Access Device Selection and Placement, §26, Standard 26.2). Большинство цитостатических химиопрепаратов, которые используются в наиболее часто назначаемых схемах химиотерапии, являются везикантами или ирритантами (табл. 1).

Не следует использовать периферические катетеры для продолжительной инфузии ирритантов, везикантов, парентерального питания или растворов с осмолярностью более $900 \mathrm{mOсм/л.}$

Для кратковременного периферического сосудистого доступа и забора проб крови рекомендуются крупные вены на предплечье. Пункция вены должна выполняться осторожно, без воздействия на сустав. Внутренняя поверхность запястья и вены нижних конечностей не должны использоваться для введения химиопрепаратов. Пункции периферических вен выше локтевой ямки (v. cephalica и v. basilica), а также вен тыльной поверхности кисти также не рекомендуются, особенно для введения препаратов кожно-нарывного действия. Следует избегать пункции вен в области лимфедемы. Пункция вен на стороне мастэктомии остаётся предметом дискуссии. Принцип выбора места для осуществления периферического сосудистого доступа изображён на рис. 1. 


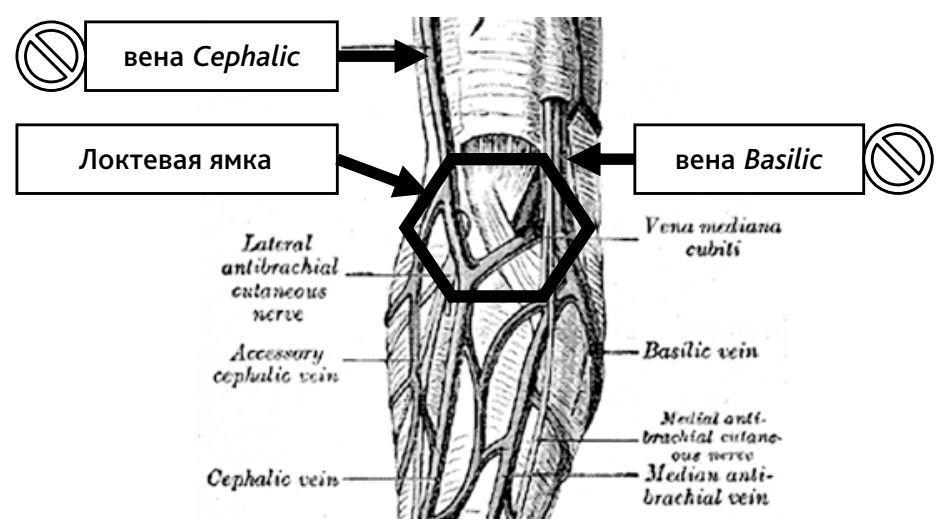

Рисунок 1. Части периферических вен серhalic и basilic.

Если прогнозируемая продолжительность периодической в/в химиотерапии у онкологических пациентов составляет более 3 месяцев, рекомендовано применять устройства длительного центрального венозного доступа, кончик катетера которых расположен в верхней полой вене (туннелируемый центральный венозный катетер, периферическиимплантируемый центральный венозный катетер (ПИК-катетер) или полностью имплантируемый порт). В верхней полой вене - самая высокая скорость венозного кровотока, турбулентный поток и низкая вязкость крови по сравнению с периферическими венами, поэтому цитотоксические препараты (ирританты и везиканты) мгновенно разбавляются до безопасной концентрации и токсическое влияние на стенку вен сводится к минимуму. Использование различных систем длительного центрального венозного доступа, в подавляющем большинстве случаев, обеспечивает возможность надежной инфузии противоопухолевых химиопрепаратов на всех этапах курсового лечения онкологических больных. Осложнения в виде экстравазации при применении систем центрального венозного доступа встречаются крайне редко и обусловлены неправильной эксплуатацией или повреждениями в результате длительных (иногда многолетних) механических нагрузок.

Назначение устройства венозного доступа для онкологического пациента осуществляет врач-онколог, а установку устройства - врач анестезиолог-реаниматолог, интервенционный или сосудистый хирург.

При выборе устройства венозного доступа следует руководствоваться следующими основными критериями:

1) Прогнозируемая продолжительность внутривенной терапии;

2) Химические свойства лекарственного (-ых) препарата (-ов);

3) Интенсивность эксплуатации (частота использования) устройства венозного доступа.

Алгоритм выбора устройства венозного доступа в онкологии представлен на рис. 2. 


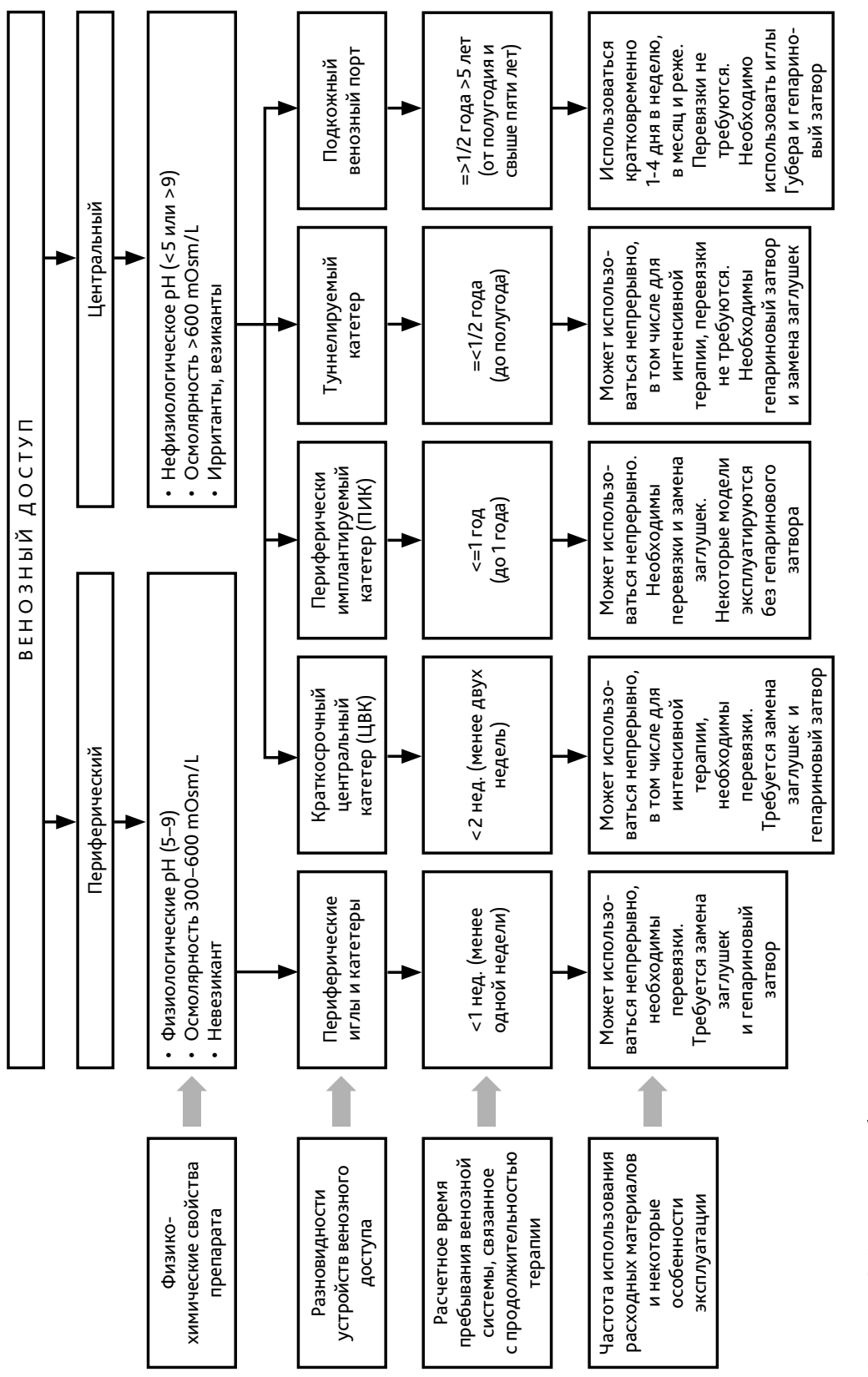

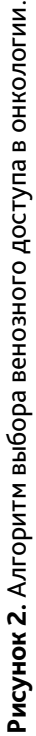


Дополнительными критериями, которые учитывают при выборе устройства венозного доступа являются следующие:

- состояние венозного русла у пациента;

- возраст пациента;

- сопутствующие заболевания;

- инфузионный анамнез пациента;

- предпочтения врача и/или пациента тому или иному виду устройств;

- возможности и оснащение (доступные ресурсы) для организации ухода за устройством;

- требуемое количество просветов у катетера (один/два/три);

- требуемая скорость инфузии;

- необходимость периодического отбора проб крови;

- будет ли терапия осуществляться амбулаторно (если планируется отпускать пациента на амбулаторное лечение, следует отдавать предпочтение устройствам венозного доступа, оснащенными встроенным клапаном, который упрощает уход за устройством и минимизирует рефлюкс крови при эксплуатации устройства);

- риск осложнений при имплантации устройства;

- $\quad$ риск пост-имплантационных осложнений;

- возможные изменения схемы лечения;

- настоящее состояние пациента;

- текущий и потенциальный уровень активности пациента;

- расходы на лечение пациента: стоимость устройства, имплантации, обслуживания и ухода.

\section{3. Дополнительные процедуры для раннего выявления и предупреждения экстравазации}

После пункции вен необходимо проверить правильность установки путём «проверки ретроградного тока крови», затем ввести 10 мл 0,9\% раствора $\mathrm{NaCl}$ для исключения экстравазации. В сомнительных случаях следует повторно ввести физиологический раствор струйно или капельно 200 мл 0,9\% раствора $\mathrm{NaCl}$. Инфузию химиопрепарата можно выполнять при полном отсутствии признаков повреждения вены, таких как ликворная подушка, дискомфорт или болезненность при продолжении инфузии 0,9\% раствора $\mathrm{NaCl}$. Следует промывать вену 10-20 мл 0,9\% раствором $\mathrm{NaCl}$ между введениями разных химиотерапевтических препаратов. Перед болюсным введением химиопрепаратов обязательна проверка тока крови. В период инфузии необходимо периодически проверять места пункции вены на наличие симптомов экстравазации: отёка, припухлости, покраснения, боли. Болюсное введение химиопрепаратов, обладающих кожно-нарывным действием, может производиться только с одновременным быстрым внутривенным введением 0,9\% раствора $\mathrm{NaCl}$. При возникновении сомнений необходимо произвести введение (струйное, капельное) 50-200 мл 0,9\% раствора $\mathrm{NaCl}$. Иногда, даже в случае правильного введения некоторых цитостатиков, могут возникать реакции, напоминающие экстравазацию: эритема, 
чувство жжения вены, крапивница, зуд. В табл. 2 представлены препараты, вызывающие местные кожные реакции и химические флебиты.

Таблица 2. Перечень препаратов, вызывающих местные кожные реакции и химические флебиты

\begin{tabular}{|l|l|}
\hline Локальные кожные реакции & Химические флебиты \\
\hline Аспарагиназа & Амзакрин \\
\hline Цисплатин & Кармустин \\
\hline Даунорубицин & Цисплатин \\
\hline Доксорубицин & Дакарбазин \\
\hline Эпирубицин & Эпирубицин \\
\hline Флударабин & 5-фторурацил \\
\hline Мехлорэтамин & Гемцитабин \\
\hline Мелфалан & Мехлорэтамин \\
\hline & Винорелбин \\
\hline
\end{tabular}

\section{3. НАБЛЮДЕНИЕ И ЛЕЧЕНИЕ ПРИ ЭКСТРАВАЗАЦИИ}

Пациент должен быть информирован о возможности экстравазации и её симптомах. При первых признаках экстравазации необходимо уведомить лечащего врача, который, в свою очередь, должен уведомить хирурга, а в случае центрального венозного доступа проконсультировать больного у анестезиолога-реаниматолога или интервенционного радиолога.

С помощью шприца необходимо удалить максимальное количество жидкости через катетер в зоне инфильтрации, при этом не следует давить на зону инфильтрации. Рекомендуется очертить зону инфильтрации и выполнить УЗИ мягких тканей в этой зоне и в дальнейшем повторять обследование для получения объективной информации о динамике процесса. Следует иммобилизовать верхнюю конечность с помощью косыночной повязки. Прерывистое охлаждение зоны инфильтрации, с помощью льда прикладываемого через пеленку, приводит к сужению сосудов, что, как правило, ограничивает распространение препарата. Холод может подавлять местные эффекты некоторых лекарственных препаратов (например, антрациклинов). Применение холода обычно рекомендуется в качестве немедленного лечения при большинстве медикаментозных экстравазаций, за исключением алкалоидов Винки. В одном сообщении о противоопухолевом лекарственном экстравазационном лечении, почти $90 \%$ экстравазаций, обработанных только местным холодом, не требовали никакого дальнейшего лечения. Локальное введение кортикостероидов не рекомендовано. Кортикостероидные препараты в стандартных терапевтически дозах могут быть назначены одномоментно или кратковременно системно для снижения воспалительной реакции только при отсутствии признаков гнойной инфекции. При назначении 
кортикостероидных препаратов следует контролировать уровень гликемии, особенно у пациентов с сахарным диабетом. С целью снижения воспалительной реакции и обезболивания целесообразно назначение препаратов НПВС. Снижению болевого синдрома способствуют аппликации $10 \%$ раствора лидокаина в виде холодного компресса или орошения аэрозольным спреем.

При экстравазации мехлорэтамина рекомендовано подкожное обкалывание тиосульфатом из расчёта по 2 мл на каждый мг мехлорэтамина. Предварительно тиосульфат разводят путём смешивания 4 мл 10\% натрия тиосульфата и 6 мл стерильной воды для инъекций. Местно применяют 30-50\% раствор диметилсульфоксида 2 раза в день на протяжении 14 дней, без втирания, укрывая стерильным перевязочным материалом. Другой вариант нанесения диметилсульфоксида - местно по четыре капли на 10 см2 поверхности кожи дважды на область предполагаемого повреждения кожи с высушиванием на воздухе без перевязки каждые 8 ч в течение 1 недели. Диметильсульфоксид должен быть нанесён как можно быстрее при экстравазации антрациклинами, митомицином С, производными платины. Необходимо помнить, что диметилсульфоксид может вызывать локальное покраснение в месте нанесения, что говорит о правильности и своевременности применения.

Дексразоксан, комплексообразующий препарат, уменьшающий токсическое действие антрациклинов на сердечную ткань, рекомендуется использовать и в случае экстравазации этих препаратов. Дексразоксан следует вводить в дозе 1000 мг/м2 в/в как можно быстрее, не позднее 6 часов, от момента экстравазации, во 2-й день - 1000 мг/м2, в 3-й день - 500 мг/м2. Доза должна быть снижена на $50 \%$ при клиренсе креатинина < 40 мл/мин. У пациентов с поверхностью тела > 2,0 м2 доза дексразоксана не должна превышать 2000 мг при введении в 1-й и 2-й дни и 1000 мг - в 3-й день. Перед добавлением в раствор дексразоксан разводится в 25 мл стерильной воды для инъекций. В течение ближайших 15 мин до и после введения дексразоксана на место экстравазации не рекомендуется наносить ни диметилсульфоксид, ни сухой холодный компресс. Побочными эффектами дексразоксана являются гематологическая токсичность, гипертрансаминаземия, тошнота, боль в месте введения.

Гиалуронидаза - энзим, вызывающий деградацию гиалуроновой кислоты и улучшающий абсорбцию препаратов, попавших под кожу; применяется при экстравазации винкаалкалоидов: 1-6 мл раствора гиалуронидазы (доза 150 Ед/мл раствора) вводят в/в через тот же катетер. Необходимое количество гиалуронидазы определяется из расчёта 1 мл раствора гиалуронидазы на 1 мл препарата, попавшего под кожу.

При некрозах, не разрешившихся в течение 10 дней и более, проводится хирургическое лечение. Обычно треть всех экстравазаций осложняется изъязвлением. В этих случаях применяется широкое иссечение некротизированных тканей и перевязки с препаратами, которые обеспечивают очищение и заживление раны с последующей пластикой раневого дефекта. Существуют также эффективные хирургические методики подкожного промывания места экстравазации, которые требуют определённой подготовки хирурга, и сегодня не рекомендованы для повседневной практики. Алгоритм лечебных мероприятий при экстравазации противоопухолевых препаратов через периферический и центральный сосудистые доступы представлены на рис. 3 и 4, соответственно. 


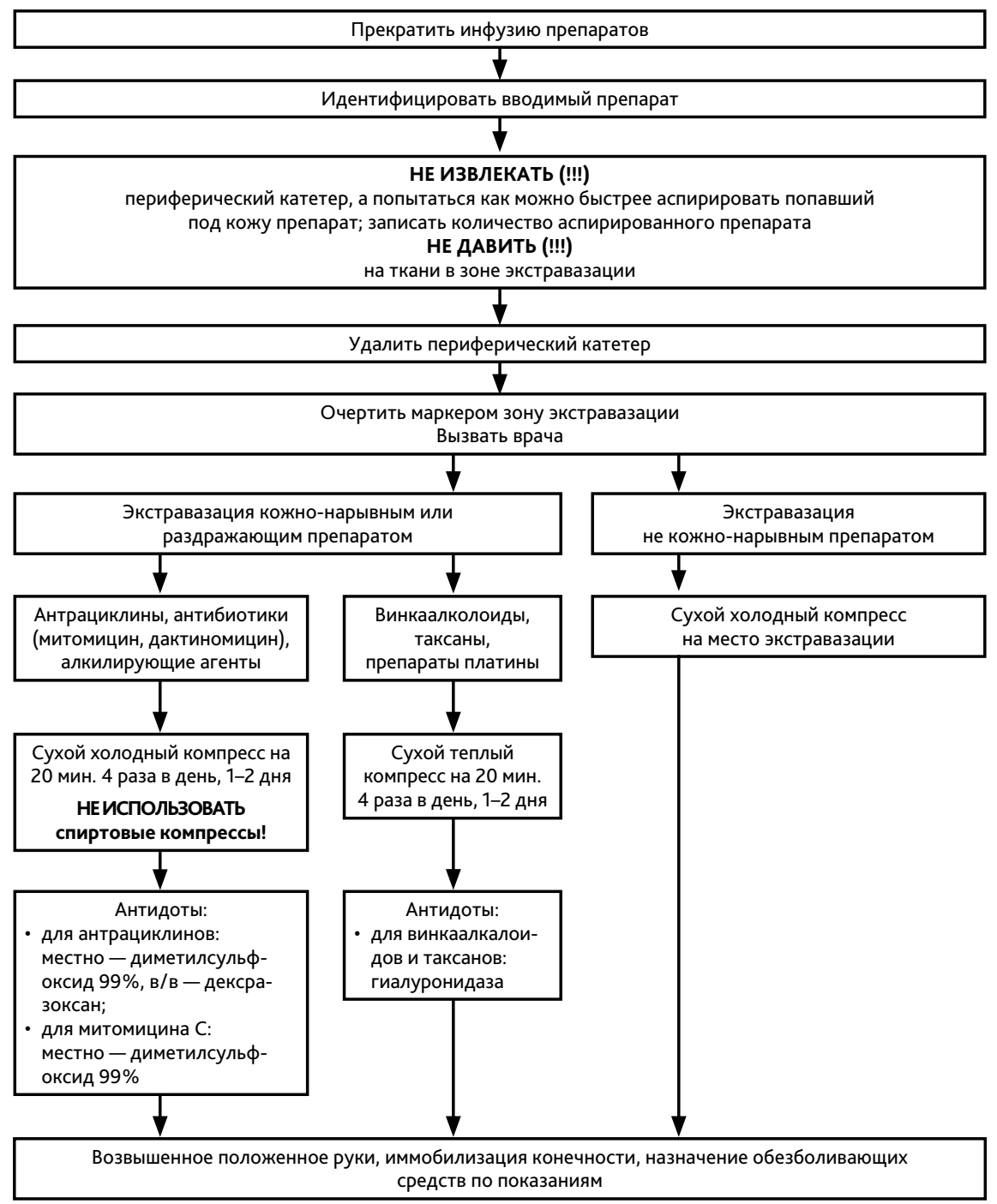

Рисунок 3. Рекомендуемый алгоритм действий при экстравазации противоопухолевых препаратов через периферический сосудистый доступ. 


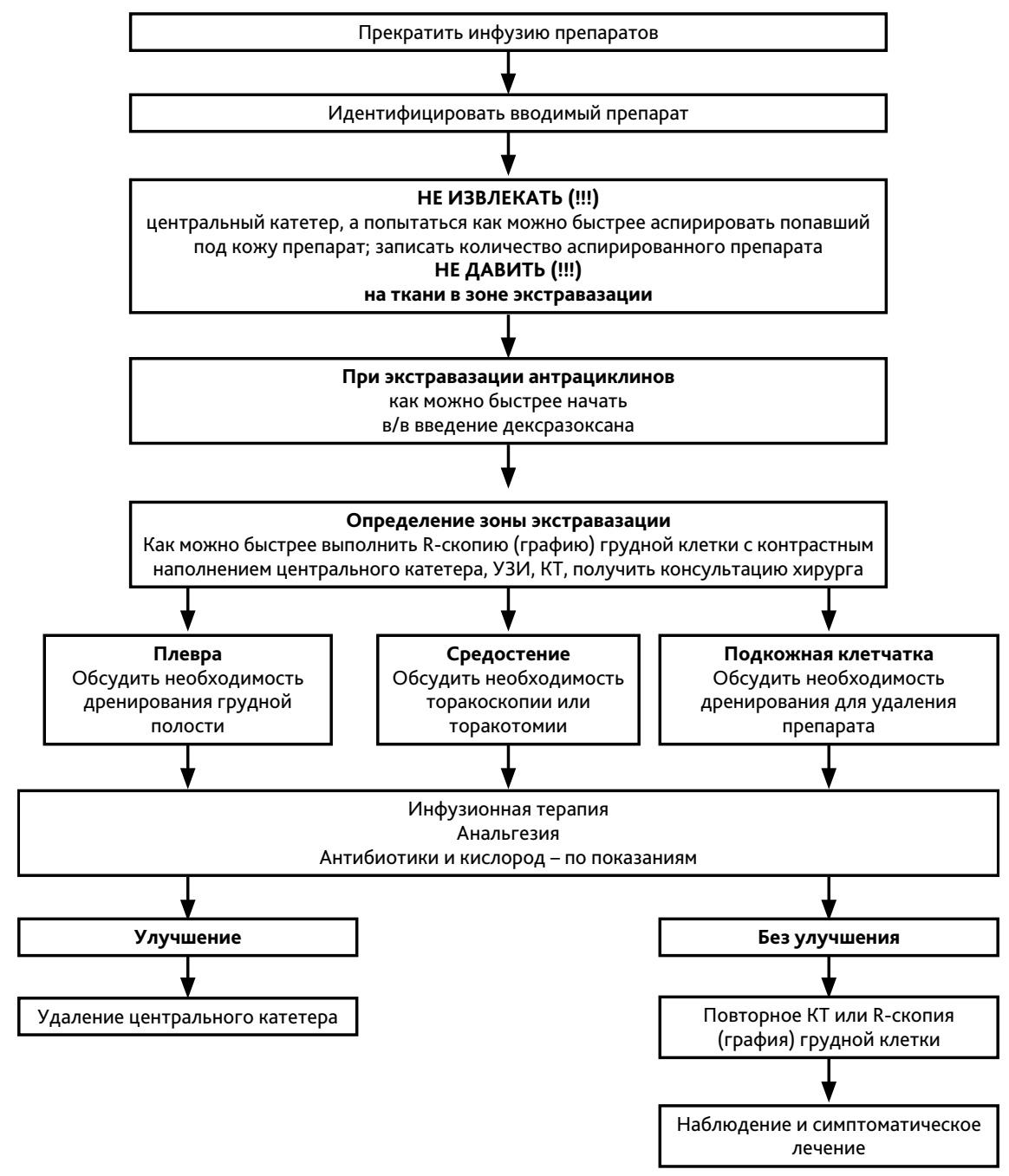

Рисунок 4. Рекомендуемый алгоритм действий при экстравазации противоопухолевых препаратов через центральный сосудистый доступ. 